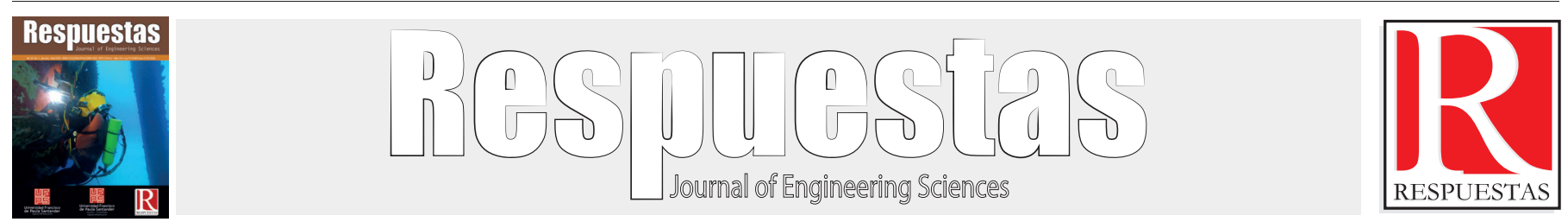

Original Article

https://doi.org/10.22463/0122820X.2406

\title{
Proposal for a semi-quantitative method for the determination of volatile compounds in cocoa liquors
}

Proposición de un método semi-cuantitativo para la determinación compuestos volátiles en licores de cacao

Cristian Palencia-Blanco ${ }^{1 *}$, Alejandra Gualdrón-Zambrano², Isabel Guarín-Henao ${ }^{3}$, Yuly Ojeda-Galeano ${ }^{4}$, Arley Villamizar

Jaimes $^{5}$, Diego Alejandro Zárate ${ }^{6}$, Roberto Antonio Coronado ${ }^{7}$, Lucero Rodriguez-Silva ${ }^{8}$, Luis Javier López-Giraldo.

I*Magíster en Ingeniería Química, kristago1204@hotmail.com, Orcid: 0000-0001-9912-1061, Universidad Industrial de Santander, Bucaramanga, Colombia.

${ }^{2}$ Ingeniera Química, alejagzar@hotmail.com, Orcid: 0000-0002-2259-3615, Universidad Industrial de Santander, Bucaramanga, Colombia.

${ }^{3}$ Ingeniera Quimica, mariguhe94@hotmail.com, Orcid: 0000-0003-1656-6175, Universidad Industrial de Santander, Bucaramanga, Colombia.

${ }^{4}$ Quimica, fernaoj41@hotmail.com, Orcid: 0000-0002-4136-8325, Universidad Industrial de Santander, Bucaramanga, Colombia.

${ }_{5}^{5}$ Magíster en Ciencia y Tecnologías Ambientales, villaja18@gmail.com, Orcid:000-0002-6042-7618, Universidad Industrial de Santander, Bucaramanga, Colombia.

${ }^{6}$ Doctor en Ciencias Biológicas, dzarate@agrosavia.co, Orcid: 0000-0001-9630-3927, Corporación Colombiana de Investigación agropecuaria, Rionegro, Colombia.

${ }^{7}$ Maestría en Desarrollo Sostenible y Medio Ambiente, rcoronado@agrosavia.co, Orcid: 0000-0002-4916-5813, Corporación Colombiana de Investigación agropecuaria, Rionegro,

Colombia.

${ }^{8}$ Profesional en producción Agroindustrial, lgrodriguezsilva@gmail.com, Orcid: 0000-0001-9454-7821, Corporación Colombiana de Investigación agropecuaria, Rionegro, Colombia. ${ }^{9}$ Doctor en Quimica, Bioquimica y Ciencias de Alimentos, ljlopez@uis.edu.co, Orcid: 0000-0001-9267-7016, Universidad Industrial de Santander, Bucaramanga, Colombia.

How to cite: C. Palencia-Blanco, A. Gualdrón-Zambrano, I. Guarín-Henao, Y. Ojeda-Galeano, A. Villamizar Jaimes, D.A. Zárate, R.A. Coronado, L. Rodriguez-Silva, L.J. López-Giraldo "Proposal for a semi-quantitative method for the determination of volatile compounds in cocoa liquors". Respuestas, vol. 25, no. 1, pp. 60-69, 2020.

Received on June 23, 2019; Approved on November 28, 2019

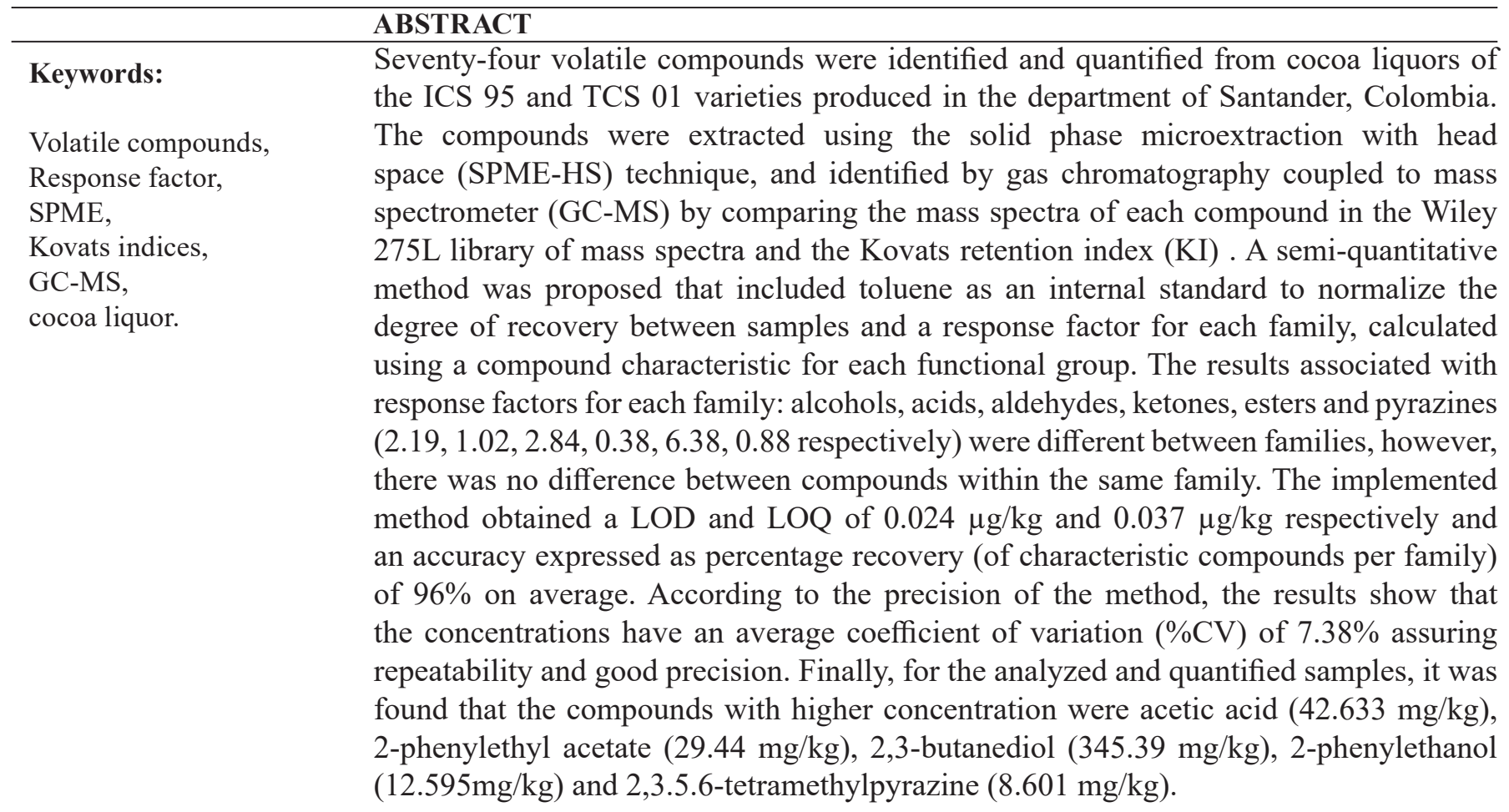

*Corresponding author.

E-mail Address:kristago1204@hotmail.com (Cristian Palencia-Blanco)

(c) $($ ) $(9$ Peer review is the responsibility of the Universidad Francisco de Paula Santander.

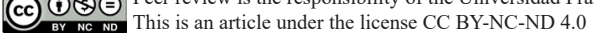




\section{RESUMEN}

Palabras clave:

Compuestos volátiles, Factor de respuesta, SPME, Índices de Kovats, GC-MS, licor de cacao.
Se identificaron y cuantificaron 74 compuestos volátiles a partir de licores de cacao de las variedades ICS 95 Y TCS 01 producidas en el departamento de Santander, Colombia. Los compuestos fueron extraídos usando la técnica de micro extracción en fase sólida con espacio de cabeza (SPME-HS), e identificados por medio de cromatografía de gases acoplado a espectrómetro de masas (GC-MS) mediante la comparación de los espectros de masas de cada compuesto en la biblioteca Wiley 275L de espectros de masa y la relación de índices de retención de Kovats (IK). Se propuso un método semicuantitativo que incluyó al tolueno como estándar interno para normalizar el grado de recuperación entre muestras y un factor de respuesta para cada familia, calculado por medio de un compuesto característico de ese grupo funcional. Los resultados asociados con los factores de respuesta para cada familia o grupo de compuestos como alcoholes, ácidos, aldehídos, cetonas, ésteres y pirazinas $(2,19,1,02,2,84,0,38,6,38,0,88$ respectivamente) fueron diferentes entre familias, sin embargo, no hubo diferencia entre los compuestos de la misma familia. El método implementado obtuvo un LOD y LOQ de $0,024 \mu \mathrm{g} / \mathrm{kg}$ y $0,037 \mu \mathrm{g} / \mathrm{kg}$ respectivamente y una exactitud expresada en porcentaje de recuperación (de los compuestos característicos por familia) en promedio de $96 \%$. Según la precisión del método, los resultados muestran que las concentraciones tienen un coeficiente de variación $(\% \mathrm{CV})$ promedio de $7,38 \%$ aseverando repetibilidad y buena precisión. Finalmente, para las muestras analizadas y cuantificadas, se encontró que los compuestos con mayor concentración fueron el ácido acético $(42,633 \mathrm{mg} / \mathrm{kg})$, acetato de 2-feniletilo (29,44 mg/kg), 2,3-butanodiol (345,39 mg/kg), 2-feniletanol (12,595mg/kg) y 2,3,5,6-tetrametilpirazina $(8,601 \mathrm{mg} / \mathrm{kg})$.

\section{Introduction}

The cocoa produced worldwide is classified into fine and flavour cocoa and ordinary or common cocoa. Only $5-10 \%$ of the cocoa produced worldwide is considered fine and aromatic [1]. Three varieties of cocoa are grown in Colombia: forastero, which corresponds to ordinary cocoa, and criollo and trinitario, which correspond to fine and aromatic cocoa. Genotype, agroclimatic conditions and processing stages have a significant impact on the aromatic quality of cocoa beans [2], [3]. This aromatic quality is directly related to the volatile aroma precursor compounds present in the different varieties [4], [5]. The greatest development of these aroma compounds is found in the processing stages (fermentation and drying) and in roasting [6], [7]. Certain volatile compounds found and identified in cocoa liquors such as 2-heptanol (floral aroma), 2-phenylethanol (sweet aroma), benzaldehyde (butter aroma), 2-phenylethylacetate (fruit aroma), acetophenone (floral aroma), 2,5-dimethylpyrazine (nutty aroma), 2-acetylpyrrole (sweet chocolate aroma), among others, favour the aromatic quality of the cocoa liquor obtained [1], [8], [9].

Although the literature is extensive on the identification of compounds associated with cocoa aroma, few articles propose methods for their quantification. Normally, quantification is carried out by means of an internal standard using a reference compound to quantify all other compounds in the sample; however, this approach is not very accurate in quantifying as a constant response factor is assumed for all compounds in the sample. Another approach to quantification is the use of external standards, in this case a reference compound is used for each compound to be quantified (the same compound for quantification); the drawback of this approach is the cost associated with the purchase of standards. Thus, for example Rodríguez-Campos et al [7], quantified some volatile compounds present in finished chocolates with external standards (one reference compound for each quantified compound) such as benzaldehyde, 2-heptanol, 2-phenylethylacetate, 2,3-diethyl-5-methylpyrzaine, among others. Additionally, they quantified the compounds for which the commercial standard was not available using the slope obtained for a standard of an analogous compound that was structurally similar, but slightly different. 10], quantified volatile compounds in cocoa powder using external standards such as benzyl acetate, ethyl octanoate, 2,3,4,6-trimethylpyrazine, acetic acid, 2-acetylpyrrole, linalool, among others, 
using a reference compound for each compound to be quantified. Similarly, Rodríguez - Campos et al applied [11] quantifying volatile compounds present in cocoa liquors at different times of fermentation and drying with external standards such as 2-phenylethylacetate, propanoic acid, 2,3,5-trimethylpyrazine, acetophenone, among others. For the compounds that did not have standards, they were quantified using an analogous compound to determine the concentration in cocoa liquors. Other authors such as Ducki et al [12], carried out the quantification of volatile compounds to cocoa powder before and after conching using external standards such as 2-methylpropanal, 3-methylbutanal, 2,3-dimethylpyrazine, 2,3,5-trimethylpyrazine, among others. For the compounds that did not have the external standard he used an internal standard (toluene) leaving as results concentrations equivalent to grams of toluene.

According to the approaches outlined in the previous paragraphs, the quantification of volatile compounds is complex due to the amount of compounds present in each sample of cocoa liquor. Therefore, the quantification of each compound using an external standard becomes impractical and economically unfeasible. For this reason, this paper identifies and proposes a semi-quantitative method by family or functional group of the volatile aroma precursor compounds present in cocoa liquors, using a hybrid strategy (internal standard - external standard/ family) which includes toluene as an internal standard to normalize the degree of recovery between samples and a response factor for each family, calculated by means of a compound characteristic of that functional group, thus facilitating the determination of the concentration (quantification) of volatile compounds present in cocoa liquors.

\section{Materials and Methods}

\section{Cocoa liquor samples}

In this study, two varieties of cocoa liquor (ICS 95 and TCS 01) were used, obtained from the research center La Suiza, Corpoica, located in Rionegro, Santander, Colombia. The cocoa beans were fermented in $15 \times 15-$ inch wooden crates for 4 days, dried in the sun and roasted at $100^{\circ} \mathrm{C}$ for 15 minutes. Two samples were taken from each variety, one with only well-fermented beans (BF) and the other with mixed beans taken at random (AZ). The selection of the well-fermented beans was done following the Colombian technical standard NTC 1252. Both BF and AZ beans were husked and ground to obtain the respective cocoa liquor.

\section{Extraction of volatile compounds from cocoa liquor}

For each sample, $2 \mathrm{~g}$ of cocoa liquor, $25 \mu \mathrm{L}$ of toluene and $20 \mu \mathrm{L}$ of the reference compound (concentration shown in Table 1), were added to a $10 \mathrm{ml}$ vial (PTFE/Silicone septa) with magnetic stirrer, where the volatiles were extracted using the solid phase microextraction technique (SPME) with a polydimethylsiloxane fiber (DVB-CAR-PDMS $50 / 30 \mu \mathrm{m}$, Supelco) [7], [12]. The sample was conditioned for $15 \mathrm{~min}$ and $60^{\circ} \mathrm{C}$ and then the extraction of volatiles was performed by introducing the fiber for $40 \mathrm{~min}$ and $60^{\circ} \mathrm{C}$.

Table I. Representative Volatile Compounds

\begin{tabular}{|c|c|c|}
\hline Reference Compound & Functional group (family) & Concentration (mg/kg) \\
\hline Toluene & Standard & 4200 \\
\hline Acetic Acid & Acid & 2070 \\
\hline Acetophenone & Ketone & 3040 \\
\hline Ethyl acetate & Ester & 2070 \\
\hline Phenylacetaldehyde & Aldehyde & 9300 \\
\hline $2,3,5$-trimethylpyrazine & Pyrazine & 2500 \\
\hline Linalol & Alcohol & 2680 \\
\hline
\end{tabular}

Separation and Identification of Volatile Compounds

Fiber desorption was performed in a gas chromatograph (GC 7890A) coupled to a quadrupole mass detector (HP 5972) with electronic impact ionization system at $70 \mathrm{eV}$ and source temperature of $230^{\circ} \mathrm{C}$. For the separation, a non-polar 5\%-phenylpolymethylsiloxane (HP-5) capillary column of $30 \mathrm{~m} \times 0.25 \mathrm{~mm} \times 0.25 \mu \mathrm{m}$ d.i. was used. The oven temperature and heating ramp for the column was set at $30^{\circ} \mathrm{C}-10 \mathrm{~min}$, then increased to $3^{\circ} \mathrm{C} /$ min- $60^{\circ} \mathrm{C}-10 \mathrm{~min}$, then increased to $10^{\circ} \mathrm{C} / \mathrm{min}-150^{\circ} \mathrm{C}$ and finally increased to $4^{\circ} \mathrm{C} / \mathrm{min}-200^{\circ} \mathrm{C}$. The carrier gas used was nitrogen at $1 \mathrm{ml} / \mathrm{min}$. The temperature of the injector was $265^{\circ} \mathrm{C}$ with injection in split mode.

The compounds were identified on the basis of two criteria:

By comparing the mass spectra of each compound in the Wiley 275L mass spec library and with the NIST MS 2.3 tool.

The calculation of the Kovats retention Index (KI) by means of equation 1 for each of the compounds and the 
respective comparison with the NIST SRD69 library to verify the identification of the compound.

$$
K I=100 \mathrm{n}+100\left[\frac{\mathrm{t}_{\mathrm{Rx}}-\mathrm{t}_{\mathrm{Rn}}}{\mathrm{t}_{\mathrm{RN}}-\mathrm{t}_{\mathrm{Rn}}}\right]
$$

\section{Equation 1. Calculation of KI}

Where:

KI: Retention rate of interest compound $\mathrm{x}$.

$\mathrm{n}$ : Number of carbon atoms of the eluting $n$-alkane before the compound of interest $x$.

$t_{\mathrm{Rx}}$ : Retention time of interest compound $\mathrm{x}$.

$t_{R n} y_{R N}:$ Retention times of $n$-alkanes eluting before and after compound $\mathrm{x}$.

\section{Quantification of volatile compounds}

To perform a more precise quantification, a semiquantitative method involving an internal standard (toluene) and a response factor for each family of compounds was proposed (Table 1). For each group of compounds (pyrazines, acids, esters, aldehydes, ketones, and pyrroles), their respective response factor was determined using equation 2. Three identical samples were prepared for each analysis and the results averaged.

$$
\mathrm{FR}=\frac{\mathrm{A}_{\mathrm{EI}} \times \mathrm{C}_{\mathrm{x}}}{\mathrm{A}_{\mathrm{x}} \times \mathrm{C}_{\mathrm{EI}}}
$$

\section{Equation 2. Response Factor Calculation}

Where:

$\mathrm{C}_{\mathrm{x}}$ : Concentration of compound of interest $\mathrm{x}$.

$A_{x}$ : Area of compound of interest $x$.

$\mathrm{C}_{\mathrm{EI}}$ : Concentration of the internal standard

$\mathrm{A}_{\mathrm{EI}}$ : Area of the internal standard.

FR: response factor.

$\rho$ : density of the cocoa liquor.

Equation 3. Calculation of analyte concentration

Once the response factors for each family were obtained, the quantification of all the volatile compounds present in the sample was carried out by means of equation 3 .

$$
C_{\mathrm{X}}(\mathrm{mg} / \mathrm{kg})=\mathrm{FR} \times \frac{A_{\mathrm{x}} \times \mathrm{C}_{\mathrm{EI}}}{A_{\mathrm{EI}} \times \rho}
$$

\section{Method validation}

In order to evaluate the analytical method, the following figures of merit were determined for the internal standard using toluene:

Limit of detection (LOD) and limit of quantification (LOQ)

LOD and LOQ were determined for the internal standard, preparing toluene solutions in ethanol, making dilutions until the minimum detectable signal was obtained.

The limit of detection (LOD) was determined with $95 \%$ confidence as the concentration in $\mathrm{mg} / \mathrm{kg}$ that provides a signal (LOD) in the detector that is significantly different from the 'target' or 'background noise' signal, according to the formula in Equation 4:

$$
L O D=\mathrm{Y}_{\mathrm{B}}+3 \mathrm{~S}_{\mathrm{B}}
$$

Equation 4. Calculation of the detection limit

Where:

$\mathrm{Y}_{\mathrm{B}}$ : Minimum detectable concentration of the analyte

$\mathrm{S}_{\mathrm{B}}$ : Standard deviation of the measurements made to determine $Y_{B}$ at a $95 \%$ confidence level.

The limit of quantification (LOQ) is defined as:

$$
L O Q=\mathrm{Y}_{\mathrm{B}}+10 \mathrm{~S}_{\mathrm{B}}
$$

Equation 5. Calculation of the limit of quantification

Intermediate accuracy

Intermediate accuracy was evaluated in terms of the coefficient of variation (CV). For the coefficient of variation the acceptance criterion $\mathrm{CV}<10 \%$ was taken into account. This value represents the relationship between mean size and variability and it is important that it is less than $10 \%$ to check for repeatability in data collection.

$$
C V=\frac{\bar{s}}{\bar{X}} * 100
$$

Equation 6. Coefficient of Variation Calculation 
Where:

$\overline{\mathrm{S}}$ : Average of the standard deviations of the concentrations of 3 repetitions for each analyte.

$\overline{\mathrm{X}}$ : Average of the concentrations of 3 replicates for each analyte.

\section{Accuracy}

The accuracy of the method was calculated on the basis of percentage recovery $(\% \mathrm{R})$, in which the sample of cocoa liquor was enriched with each of the compounds used as reference for each family with their respective concentrations shown in Table 1 (all experiments were done in triplicate and their response was averaged). The calculation was made as follows:

$$
\% R=\frac{\mathrm{C}_{\mathrm{ME}}-C_{A}}{C_{T}} \times 100
$$

Equation 7. Calculation of the recovery percentage

Where:

$\mathrm{C}_{\mathrm{ME}}$ : Concentration of the measured analyte in the fortified sample

$\mathrm{C}_{\mathrm{A}}$ : Concentration of the analyte in the sample without fortification

$\mathrm{C}_{\mathrm{T}}$ : Total concentration of the analyte added to the sample

\section{Results and Discussion}

\section{Identification and quantification of volatile compounds}

Seventy-four volatile compounds were identified and quantified in cocoa liquors from the department of Santander. Table 3 shows the identification and quantification by functional group of each sample of cocoa liquor obtained. Identification results similar to those obtained here were reported by [3], [6], [7], [10], [12], [13], among others, showing that most of the identified compounds are pleasant and associated with desired sensory attributes. Thus, for example, the presence of benzaldehyde, phenylacetaldehyde, 2-phenyl-2-butenal, 2,3 butanediol, 2-heptanol, linalool, 2-phenyl-ethanol, 3-hydroxy-2-butanone, 2-heptanone, 2-nonanone, 3-methyl-butanol acetate is beneficial, ethyl acetate, ethyl octanoate, 2,3,5,6-tetramethyl pyrazine, 1-(1h-pyrrol-2-yl) ethanone for the sensory characteristics of cocoa, providing mostly cocoa, sweet, nutty and fruity sensory notes. Looking at table
3 , it was found that esters and alcohols constituted the families with the highest number of aroma compounds found in the 4 cocoa liquors and these represent $23 \%$ and $16 \%$ respectively of the total number. On the other hand, other compounds were found that have not been reported in cocoa matrices such as 2-ethylbutanoic acid, 3-methyl-2-cyclohexanone, epoxy linalol (6-ethenyl-2,2,6-trimethyloxan-3-ol), gamma-terpinene (1-methyl-4-(1-methyl ethyl)- 1,4-cyclohexadiene), 4-carvomenthenol (4-methyl-1-(1-methylethyl)-3cyclohexenol), 1-methylpropyl acetate (sectile acetate), isobutyl isobutyrate (2-methylpropanoate), cis-citral (3,7-dimethyl-2,6-octadienal), trans-citral (3,7-dimethyl2,6-octadienal).

With respect to the family of acids, 6 acids were identified and are shown in table 3. It is observed that the concentrations of the acids in the random samples are much higher than the well-fermented samples, showing a reduction when comparing the $\mathrm{BF}$ samples to the $\mathrm{AZ}$ samples (TCS 33\% and ICS 14\% reduction), this is due to the selection of only well-fermented beans which denote a good fermentation process. Analyzing the behavior of acetic acid (a compound with a higher concentration; associated with perceptions of vinegar) the reduction in the TCS01 and ICS95 cocoa liquor samples was $34.7 \%$ and $12.2 \%$ respectively. The concentration of acetic acid in the TCS 01AZ sample is higher in all samples which could then lead to the hypothesis that TCS 01AZ would have undesirable attributes associated with vinegar, sour and astringent notes [13] - these characteristics are associated with under-fermented cocoa beans. However, a sensory analysis would be required to support the hypothesis made in the previous paragraph and to determine the threshold concentration at which undesirable attributes are perceived. Likewise, this work identified the presence of an unreported compound, 2-ethylbutanoic acid, which has odor-active characteristics associated with rancid, acid.

Eleven alcohols were identified, of which 2-phenylethanol and $\beta$-linalool have been found in various cocoa matrices [3], [10]. For this family of compounds, the BF samples increased the concentrations of 2,3-butanediol, 2-nonanol, and 2-phenylethanol (the first two odorless; the last one associated with sweet, floral) [6], [11] while the concentrations of 3-methylbutanol (butter flavor), and 2-heptanol (floral) were reduced. Two steroisomers of the compound 2,3-butanediol were found, showing a 
considerable increase when only BF grains are selected; in the sample TCS01BF, this compound increases approximately 18 times its concentration with respect to TCS01AZ. Similar to the other steroisomer in the TCS01BF sample where the increase is 3 times the concentration in TCS01AZ. In the ICS 95 samples there is an increase for the BF samples (ICS95BF increase 1.2 times over ICS95AZ), however, it is not as significant as in the TCS01 variety. Compounds such as 2-ethylhexanol, 2,6-octadien-1-ol-3,7-dimethyl and phenylmethanol (associated with attributes such as sweet and floral) [10], were only identified in TCS $01 \mathrm{BF}$; their presence is possibly associated with an increase in the number of well-fermented beans and with the genetics of TCS 01. In this sense, TCS 01 is an acriolated trinitarian clone with a theobromine/caffeine ratio of 4; while ICS 95 is a normal trinitarian with a ratio of 8 .

For aldehydes and ketones, 12 and 5 compounds were identified respectively. As shown in table 3, most of the aldehydes increase their concentration in the BF samples with respect to the AZ samples (TCS $77 \%$ and for ICS $7 \%$ increase), this is due to the increase of well-fermented grains that give as effect an increase in concentrations of desired volatile compounds. benzaldehyde, phenylaceltadehide and 5-methyl-2-phenyl-2-hexenal are the aldehydes with the highest concentration found in the samples and widely reported in the literature on cocoa matrices [6], [7]; they represent $65 \%$ (TCS 01 ) and $56 \%$ (ICS 95) of the total increase in aldehyde concentration between the BF and AZ samples. Aldehydes not reported and identified were 3,7-dimethyl-2,6-octadienal (ciscitral) and 3,7-dimethyl-2,6-octadienal (trans-citral) with lemon citrus (PubChem) flavours. The 2-Phenyl2-butenal, 4-methyl-2-phenyl-2-pentenal and 5-methyl2-phenyl-2-hexenal offering cocoa aromas increase their concentration by $30 \%$ (TCS01) and 14\% (ICS95) when only well-fermented beans are selected. These compounds are representative of the cocoa fruit because it is a constituent of the characteristic cocoa aroma. On the other hand, the most commonly reported ketones in cocoa matrices are 3-hydroxy-2-butanone (butter aroma), acetophenone (strong sweet aroma) and 2-heptanone [3], as well as in table 3 are the ketone compounds with the highest concentration. However, this functional group is found in higher concentration in the AZ samples than in the BF samples ( $43 \%$ and $21 \%$ reduction in TCS $01 \mathrm{BF}$ and ICS 95 BF respectively). 3-methyl-2-cyclohexanone was identified which has not been found in other reports in cocoa matrices obtaining a sweet, nutty aroma. Seventeen esters were identified among which 3-methylbutyl acetate, ethyl benzoate, ethyl octaonate, isoamyl benzoate, and ethyl 2-phenyl acetate have been reported in investigations associated with the identification of volatile cocoa compounds and pleasant fruit and candy flavors [7], [3]. These compounds show a reduction in BF samples of $30 \%$ (TCS01BF) and 17\% (ICS95BF) with respect to AZ samples. Unlike the two compounds with higher concentrations present in the samples such as 2-phenylethyl acetate and ethyl acetate with sensory properties to sweet, fruity [6], [3]. which increase their concentration significantly in the TCS01BF sample by 8 and 3.2 times and in the ICS95BF sample by 1.2 and 1.1 times. Isobutyl isobutyrate has not been reported in other investigations, but in this work it was identified only in the TCS 01 BF variety and was one of the main compounds with higher concentration and odor-active fruit aroma (PubChem). The compounds 3-methylbutyl acetate, 2-methylbutyl acetate and 3-methyl-2-butyl acetate with fruit aroma are reduced by $47 \%$ (TCS01BF) and $21 \%$ (ICS95BF) in the BF samples due to the elimination of 2-methylbutanoic and 3-methylbutanoic acids which are the precursors of these compounds in the fermentation and drying stages [10], compounds such as ethyl 3-phenyl-2-propenoate associated with sweet and cinnamon aromas and benzyl acetate with floral and fruit aromas [10], are only found in the TCS 01 variety and increase their concentration by 2.3 and 1.6 times when working with $\mathrm{BF}$ grains. 
Table III. Volatile compounds identified and quantified in cocoa liquors from ICS-95 and TCS-01 materials

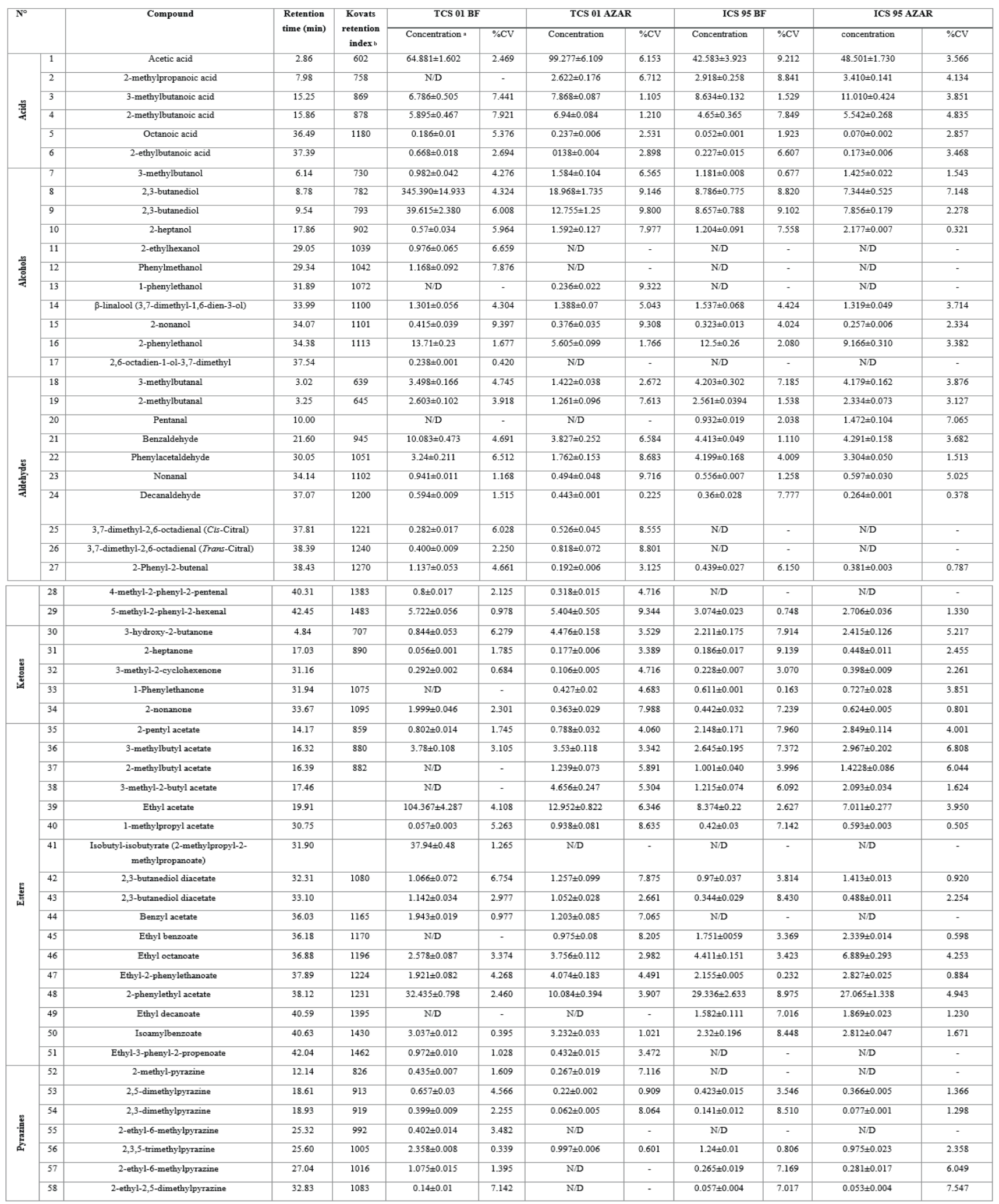




\begin{tabular}{|c|c|c|c|c|c|c|c|c|c|c|c|c|}
\hline & 59 & 2,3,5,6-tetramethylpyrazine & 33.32 & 1090 & $30.826 \pm 0.348$ & 1.128 & $7.53 \pm 0.227$ & 3.014 & $8.709 \pm 0.269$ & 3.088 & $7.390 \pm 0.371$ & 5.020 \\
\hline & 60 & 2-ethyl-3,5,6-trimethylpyrazine & 35.96 & 1163 & $0.611 \pm 0.037$ & 6.055 & N/D & - & N/D & - & N/D & - \\
\hline & 61 & 2,3,5-trimethyl-6-propylpyrazine & 36.64 & & $0.093 \pm 0.003$ & 3.225 & N/D & - & N/D & - & N/D & - \\
\hline \multirow{5}{*}{ 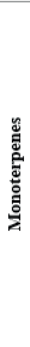 } & 62 & $\begin{array}{c}\beta \text {-pinene(6,6-Dimethyl-2-methylene bicyclo } \\
{[3.1 .1] \text { heptane) }}\end{array}$ & 22.63 & 963 & $0.56 \pm 0.039$ & 6.964 & $0.435 \pm 0.003$ & 0.689 & N/D & - & $\mathrm{N} / \mathrm{D}$ & - \\
\hline & 63 & $\begin{array}{c}\beta \text {-myrcene (1,6-Octadiene-7-methyl-3- } \\
\text { methylene) }\end{array}$ & 24.48 & 983 & $0.562 \pm 0.041$ & 7.295 & $0.418 \pm 0.002$ & 0.478 & $0.584 \pm 0.035$ & 5.993 & $0.525 \pm 0.008$ & 1.523 \\
\hline & 64 & $\begin{array}{l}\text { a-limonene (1-methyl-4- (1-methyl-ethenyl) - } \\
\text { cyclohexene) }\end{array}$ & 28.02 & 1028 & $13.933 \pm 1.103$ & 7.916 & $9.861 \pm 0.539$ & 5.465 & $6.808 \pm 0.343$ & 5.038 & $6.237 \pm 0.388$ & 6.220 \\
\hline & 65 & $\begin{array}{l}\gamma \text {-Terpinene (1-methyl-4- (1-methyl-ethyl) -1,4- } \\
\text { cyclohexadiene }\end{array}$ & 31.49 & 1064 & $3.848 \pm 0.319$ & 8.290 & $1.679 \pm 0.142$ & 8.457 & $1.787 \pm 0.084$ & 4.700 & $1.058 \pm 0.022$ & 2.079 \\
\hline & 66 & $\begin{array}{l}\text { 4-carvomenthenol (4-methyl-1- (1-methylethyl) } \\
\text {-3-cyclohexenol) }\end{array}$ & 36.32 & 1177 & $0.661 \pm 0.015$ & 2.269 & $0.161 \pm 0.008$ & 4.968 & ND & - & ND & - \\
\hline \multirow{8}{*}{ 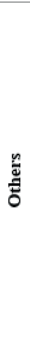 } & 67 & 2-acetylfuran & 9.67 & 802 & N/D & - & N/D & - & $0.336 \pm 0.024$ & 7.142 & $0.488 \pm 0.015$ & 3.073 \\
\hline & 68 & 2(3H) -dihydro furanone & 18.50 & 910 & N/D & - & $0.12 \pm 0.009$ & 7.500 & $0.26 \pm 0.022$ & 8.461 & $0.244 \pm 0.015$ & 6.147 \\
\hline & 69 & 1,2,3-trioxane-2,4,6-trimethyl & 20.38 & & $2.852 \pm 0.117$ & 4.102 & $5.01 \pm 0.361$ & 7.205 & $1.829 \pm 0.105$ & 5.740 & $2.443 \pm 0.133$ & 5.444 \\
\hline & 70 & Benzonitrile & 23.66 & 979 & $0.498 \pm 0.003$ & 0.602 & $0.456 \pm 0.025$ & 5.482 & N/D & - & $\mathrm{N} / \mathrm{D}$ & - \\
\hline & 71 & 1- (1h-pyrrol-2-yl) ethanone (2-acetilpirrol) & 32.06 & 1076 & $0.885 \pm 0.047$ & 5.310 & $0.366 \pm 0.014$ & 3.825 & $0.54 \pm 0.053$ & 9.814 & $0.543 \pm 0.034$ & 6.261 \\
\hline & 72 & $\begin{array}{l}\text { 6-methyl-3,5-dihydroxy-2,3-dihydro-4h-pyran- } \\
\text { 4-one }\end{array}$ & 35.40 & 1149 & $1.419 \pm 0.107$ & 7.540 & $1.418 \pm 0.053$ & 3.737 & $1.156 \pm 0.087$ & 7.525 & $1.006 \pm 0.010$ & 0.994 \\
\hline & 73 & 6-ethenyl-2,2,6-trimethyloxan-3-0 & 36.30 & 1173 & $0.811 \pm 0.022$ & 2.712 & $0.3 \pm 0.008$ & 2.666 & $0.510 \pm 0.018$ & 3.529 & $0.389 \pm 0.007$ & 1.799 \\
\hline & 74 & 2-furancarboxaldehyde & 12.71 & 835 & $1.234 \pm 0.044$ & 3.565 & $0.476 \pm 0.023$ & 4.831 & N/D & - & N/D & - \\
\hline
\end{tabular}

${ }^{a}$ Concentrations in $\mathrm{mg} / \mathrm{kg}$, ${ }^{\mathrm{b}}$ Compared with literature, N/D Not determined

Ten pyrazines were identified in the four samples of processed cocoa liquor, among which 2,5-dimethylpyrazine, 2,3,5-trimethylpyrazine and 2,3,4,6-tetramethylpyrazine are widely found in roasted cocoa liquor offering aromas of nuts, roasted and dried fruits [6], [5]. Table 3 shows that there is an increase in the concentration of these compounds when $\mathrm{BF}$ grains are chosen. In the TCS 01BF sample, the concentration is increased by 4 times compared to the AZ sample, and the ICS95BF sample is increased by 1.2 times. In the same way, [5], they show that for grains with better indications of fermentation, the concentrations of pyrazines increase due to the increase in compounds that develop in the miallard reaction in the roasting stage. In the TCS 01 variety, this type of compound stands out due to the characteristics of tri-cryolated cocoa, which is why a greater quantity of pyrazine compounds is developed, as opposed to the ICS 95 variety, which only develops 6 of the 10 compounds found. For this reason it would be expected that this genotype has a greater richness in compounds with characteristics of fine and aroma.

Some monoterpenes were identified in the samples as beta-pinene, beta-myrcene, alpha-limonene, gammaTerpine and 4-carvomentenol, with floral and herbal sensory characteristics (PubChem, MSDS, Kadow). Like pyrazines, these compounds increase their concentration when $\mathrm{BF}$ grains are chosen $(56 \%$ TCS01BF and
$18 \%$ ICS95BF). Compounds such as beta-pinene and 4-carvomentenol only develop in the TCS01 variety, in concentrations of $0.560 \mathrm{mg} / \mathrm{kg}$ and $0.661 \mathrm{mg} / \mathrm{kg}$ increasing 4 and 1.2 times their concentration respectively, while $\alpha$-limonene obtained a concentration of $13.933 \mathrm{mg} / \mathrm{kg}$, being the monoterpene with the highest concentration. Other families of compounds identified are furanes, oxanes, pyrroles and pyrones. However, few compounds from these functional groups are found in the samples and, moreover, in low concentrations. For example, the 2-furancarboxaldehyde that offers aroma to candy, almonds [10], Pubchem, and obtained a concentration of $1.234 \mathrm{mg} / \mathrm{kg}$ increasing 2.5 times its concentration with respect to the AZ sample and the benzonitrile that offers aromas to almonds [10], Pubchem, which maintained its concentration between BF and AZ grains; these two were only found in the variety TCS 01 . The 2-acetylpyrrole that offers aromas of chocolate, hazelnut 6-methyl-3.5dihydroxy-2.3-dihydro-4h-pyran-4-one which is odorless but has the highest concentration of the other compounds which is $1.419 \mathrm{mg} / \mathrm{kg}$ in the variety TCS 01-BF. B. and 1,2,3-trioxane-2,4,6-trimethyl with higher concentrations in the random samples as $5.01 \mathrm{mg} / \mathrm{kg}$ in TCS 01-AZ and $2.443 \mathrm{mg} / \mathrm{kg}$ ICS 95-AZ. 


\section{Method validation}

\section{$L O D \& L O Q$}

A minimum detected concentration of $0.0186 \mu \mathrm{g} / \mathrm{kg}$ was obtained and equations 1 and 2 were used to calculate the LOD and LOQ, which are $0.024 \mu \mathrm{g} / \mathrm{kg}$ and $0.037 \mu \mathrm{g} /$ $\mathrm{kg}$, respectively, which may offer high sensitivity. Similar limits were found in other investigations using the SPME solid phase micro extraction technique.

Intermediate accuracy

Table 3 shows each of the coefficients of variation ( $\% \mathrm{CV}$ ) associated with the determination of concentrations for each of the identified compounds. The results reveal that in none of the cases did the CV value exceed $10 \%$. This result is an indication that the standardized method achieves reliable results, guaranteeing repeatability and consequently good precision. Other authors who have also worked with extraction of volatile compounds by means of SPME from other matrices such as coffee and wines, cheeses, obtaining average $\% \mathrm{CV}$ values less than $10 \%$ for alcohols, ketones, aldehydes, esters and acids similar to those reported in this work.

\section{Accuracy}

Table 4 shows the recovery percentages for each of the families of compounds worked on. The percentages obtained range from $86 \%-94 \%$, with the lowest recovery for acidic compounds and the highest for pyrazines.

Tabla IV. Percentage of recovery for each of the representative compounds of each family

\begin{tabular}{|c|c|}
\hline Compound family & Recovery rate (\%R) \\
\hline Acid & 86.11 \\
\hline Alcohols & 90.74 \\
\hline Aldehydes & 91.60 \\
\hline Ketones & 91.51 \\
\hline Esters & 92.38 \\
\hline Pyrazines & 93.40 \\
\hline
\end{tabular}

These percentages show a high recovery capacity of the compost to achieve an accurate quantification [10].

\section{Response factors}

Figure 1 shows the mean values of the response factors, the standard deviation and the coefficients of variation for each of the families of compounds. It can be seen that for the groups of compounds such as pyrazines, esters, ketones, pyrroles and aldehydes the percentages of coefficient of variation were less than $6 \%$. The response factor of the acids slightly exceeded the limit value of $10 \% \mathrm{CV}$; this behaviour is associated with the elution difficulties presented by the chromatographic peak for the acid that was selected as the reference compound. Due to this, it is observed that there is repeatability in the determination of the response factors.

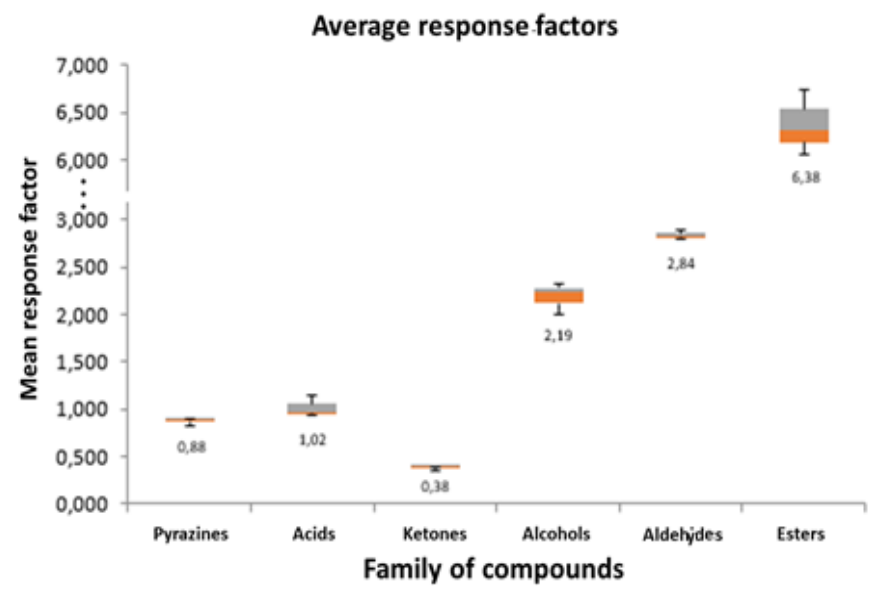

\begin{tabular}{|c|c|c|c|}
\hline Composite Family & Average & DS & \% CV \\
\hline Pyrazines & 0.88 & 0.04 & 4.61 \\
\hline Esters & 6.38 & 0.35 & 5.465 \\
\hline Acids & 1.02 & 0.11 & 11.17 \\
\hline Ketones & 0.38 & 0.02 & 4.456 \\
\hline Alcohols & 2.19 & 0.17 & 7.974 \\
\hline Pirroles & 1.1 & 0.02 & 1.787 \\
\hline Aldehydes & 2.84 & 0.05 & 1.614 \\
\hline Monoterpenes & $\mathrm{ND}^{*}$ & $\mathrm{ND}^{*}$ & $\mathrm{ND}^{*}$ \\
\hline Others & $\mathrm{ND}^{*}$ & $\mathrm{ND}^{*}$ & $\mathrm{ND}^{*}$ \\
\hline
\end{tabular}

*ND $=$ not determined. For the quantification we worked with a response factor equal to 1 , following the internal standard approach without family approximation.

Figure 1. Response factors by compound family

\section{Conclusion}

Semi-quantitative methods have proven to be a valuable tool for the quantification of volatile compounds. The hybrid technique presented in this paper shows good levels of reliability and reproducibility for the quantification of volatile compounds in cocoa matrices. 


\section{References}

[1] A. Aprotosoaie, S. Luca and A. Miron, "Flavor Chemistry of Cocoa and Cocoa ProductsAn Overview: Flavor chemistry of cocoa", Comprehensive Reviews in Food Science and Food Safety, vol. 15, pp. 73-91, 2016.

[2] S. Beckett, "Industrial chocolate manufacture and use (John Wiley \& Sons)", 4th edition, 2011.

[3] A. Pallares-Pallares, J. Perea-Villamil and L. López-Giraldo, "Impacto de las condiciones de beneficio sobre los compuestos precursores de aroma en granos de cacao (Theobroma cacao L) del clon CCN-51", Respuestas, vol. 21, no. 1, pp. 120-133, 2015.

[4] M. Amaiz, R. Gutiérrez, E. Pérez and C. Álvarez, "Efecto del tostado sobre las propiedades físicas, fisicoquímicas, composición proximal y perfil de ácidos grasos de la manteca de granos de cacao del estado Miranda, Venezuela", Revista Cientifica UDO Agrícola, vol. 12, pp. 439-446, 2012.

[5] S. Jinap, W. Rosli, A. Russly and L. Nordin, "Effect of roasting time and temperature on volatile component profiles during nib roasting of cocoa beans (Theobroma cacao)", Journal of the Science of Food and Agriculture, vol. 77, pp. 441-448, 1998.

[6] E. Afoakwa, A. Paterson, M. Fowler and A. Ryan, "Flavor Formation and Character in Cocoa and Chocolate: A Critical Review". Critical Reviews in Food Science and Nutrition, vol. 48, pp. 840$857,2008$.

[7] J. Rodriguez-Campos, H. Escalona-Buendía, I. Orozco-Avila, E. Lugo-Cervantes and M. Jaramillo-Flores, "Dynamics of volatile and nonvolatile compounds in cocoa (Theobroma cacao L.) during fermentation and drying processes using principal components analysis", Food
Research International, vol. 44, no. 1, pp. 250258, 2011.

[8] C. Counet, D. Callemien, C. Ouwerx and S. Collin, "Use of Gas Chromatography-Olfactometry To Identify Key Odorant Compounds in Dark Chocolate. Comparison of Samples before and after Conching", Journal of Agricultural and Food Chemistry, vol. 50, pp. 2385-2391, 2002.

[9] M. Jati and A. Sari, "Analysis of Pyrazine and Volatile Compounds in Cocoa Beans Using Solid Phase Microextraction. Pelita Perkeb", Coffee and Cocoa Research Journal, vol. 27, 2011.

[10] J. Bonvehí, "Investigation of aromatic compounds in roasted cocoa powder", European Food Research and Technology, vol. 221, pp. 1929, 2005.

[11] J. Rodriguez-Campos, H. Escalona-Buendía, S. Contreras-Ramos, I. Orozco-Avila, E. Jaramillo-Flores and E. Lugo-Cervantes, "Effect of fermentation time and drying temperature on volatile compounds in cocoa", Food Chemistry, vol. 132, no. 1, pp. 277-288, 2012.

[12] S. Ducki, J. Miralles-Garcia, A. Zumbé, A. Tornero and D. Storey, "Evaluation of solid-phase micro-extraction coupled to gas chromatographymass spectrometry for the headspace analysis of volatile compounds in cocoa products", Talanta, vol, 74, pp. 1166-1174, 2008.

[13] J. Misnawi and B. Ariza, "Use of Gas Chromatography-Olfactometry in combination with Solid Phase Micro Extraction for cocoa liquor aroma analysis", International Food Research Journal, vol. 18, 2011. 